\title{
Relative competition between white clover and weed species Silene gallica
}

\author{
Dalvane Rockenbach ${ }^{1, \star}(\mathbb{D})$, Andrisa Balbinot ${ }^{1}$ (D), Marlon Ouriques Bastiani ${ }^{1}$ (D), Fernanda Cassiane \\ Caratti $^{1}$ (D), Dirceu Agostinetto ${ }^{1}$ (D), Fabiane Lamego ${ }^{2}$ (D) \\ 1. Universidade Federal de Pelotas - Departamento de Fitossanidade - Pelotas (RS), Brazil. \\ 2. Embrapa Pecuária Sul-Bagé (RS), Brazil. \\ Received: Mar. 25, 2021 | Accepted: Sep. 13, 2021 \\ Section Editor: Gabriel Constantino Blain \\ *Corresponding author: dalvane.rockenbach@gmail.com \\ How to cite: Rockenbach D, Balbinot A, Bastiani MO, Caratti FC, Agostinetto D, Lamego F. Relative competition between white clover and \\ weed species Silene gallica. Bragantia, 80, e6021. https://doi.org/10.1590/1678-4499.20200121
}

\begin{abstract}
The aim of the present study was to assess the relative competition between white clover (cv. BRS URS Entrevero) and weed species Silene gallica $\mathrm{L}$. through replacement series. The experiments followed a completely randomized design with four replications. The first study showed that the shoot dry mass of both species (white clover and S. gallica) became constant with 16 plants.pot ${ }^{-1}$ or 400 plants. $\mathrm{m}^{-2}$. In 2017, a study was conducted and it was repeated in 2018 in order to assess white clover competition with $\mathrm{S}$. gallica under different crop:weed proportions pot ${ }^{-1}(100: 00 ; 75: 25 ; 50: 50 ; 25: 75$ and 00:100). Competitiveness analysis was carried out through diagrams applied to replace experiments and through the relative competition indices. Morphological parameters such as plant height, leaf area and shoot dry mass of the crop and the weed were measured when S. gallica plants bloomed (105 days after species emergence). Results have proven the phenotypic plasticity of temperate-climate foragers such as white clover. This outcome shows that the competitive relationship with Silene gallica changes due to plant proportions composing the association. Therefore, it was possible to conclude that the species show similar competitive ability.
\end{abstract}

Key words: competitiveness, replacement series, seed production, temperate-climate forage.

\section{INTRODUCTION}

The competition skills of a certain species are related to its ability to efficiently use resources available in the environment where it is distributed in (Rizzardi et al. 2001). Radosevich et al. (2007) listed three essential factors to predict the competition relationship between weeds and crops: emergence time, spatial arrangement, and establishment speed. The establishment of temperate-climate foragers such as white clover (Trifolium repens L.) is slow (Barcellos et al. 2008). Therefore, they must establish in the absence of other competitive plants in order to avoid losses due to competition with other weeds in their early development stages and to assure their full establishment and development (Lustosa et al. 2011). White clover yield losses due to competition with other species can reach 96\% (Schuster et al. 2013), and this number shows that this forage species tends to deeply feel the effects of competition.

Knowing the interaction between crops and weeds is the way to find important information about real management needs and the ideal moment for management practices. White clover was the species, among all other clover species, presenting the best association between weed suppression and yield losses (Den Hollander et al. 2007), a fact that evidences a certain balance in their competition relationship. However, this response can present variations depending on the weed species in the competition.

Based on Normative Instruction no. 46/2013, Silene gallica L. is the species producing tolerated harming seeds in areas of Lotus corniculatus and white clover production in Southern Brazil (Brasil, 2013). Its occurrence (above the allowed levels) in the assessed lots can make them infeasible and impair the trade and availability of certified seeds in the market. 
The hypothesis advocated in the present study lied on the assumption that S. gallica is less competitive than white clover when it comes to population ratio. Thus, the aim of the present study was to assess the relative competition ability of white clover against weed species $S$. gallica based on the replacement series method.

\section{MATERIALS AND METHODS}

Three experiments were carried out in greenhouse at Faculdade de Agronomia Eliseu Maciel, of Universidade Federal de Pelotas (UFPel), between 2016 and 2018. The first experiment was installed in June 2016 and consisted in conducting white clover and weed (S. gallica) monocrops. The aim of this previous study was to set the plant populations whose shoot dry mass (SDM) per site unit becomes constant and disregards population by applying the "law of constant final yield" (Radosevich et al. 2007). The tested forage and weed populations corresponded to 2, 4, 8, 16 and 32 plants.pot $^{-1}$ (equivalent to $50,100,200,400$ and 800 plants. $\mathrm{m}^{-2}$ ).

The study followed a completely randomized design, with four replications. The used white clover seeds cv. BRS URS Entrevero were provided by Empresa Brasileira de Pesquisa Agropecuária (Embrapa). Silene gallica seeds were collected in the field, in the experimental site of Herbology Center (CEHERB) of the Department of Crop Protection of UFPel, Capão do Leão (RS). Experimental units consisted of 8-L/23-cm-diameter pots filled with soil brought from the agricultural area of UFPel.

SDM production was determined at the beginning of S. gallica plants reproduction period by weighing the collected mass after its drying in forced air circulation oven at $60^{\circ} \mathrm{C} \pm 5^{\circ} \mathrm{C}$ until it reached constant weight.

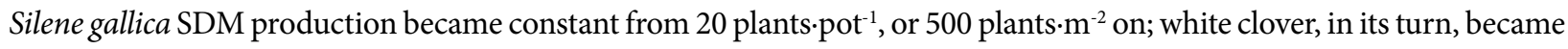
constant from 16 plants.pot ${ }^{-1}$, or 400 plants. $\mathrm{m}^{-2}$ on. The mean number of plants from each species was calculated in order to determine the plant ratios to be used-the calculations were adjusted to allow plant distribution in ratios necessary to carry out the replacement series method. The final population of 16 plants.pot ${ }^{-1}$ or 400 plants $\cdot \mathrm{m}^{-2}$ were used in the experiment (data not shown).

Based on results recorded for the previous experiment, two studies were conducted according to the replacement series in June 2017 (first year); they were repeated in June 2018 (second year). The replacement series comprised the following white clover: S. gallica ratios: 100:0 (monoculture of forage); 75:25; 50:50; 25:75; and 100:0\% (monoculture of the competitor plant). These ratios were sown in 8-L pots filled with $8 \mathrm{~kg}$ of soil; they were irrigated whenever necessary to keep soil humidity at field capacity. Population larger than the desired one was sown in order to assure the ideal population in the pots; population adjustment was performed at plantlet establishment. Treatments followed a completely randomized design, with four replications.

Variables were determined at the beginning of $S$. gallica plants' reproduction period: plant height (PH), leaf area (LA) and the SDM of the forage and competitor plants. Plant height $(\mathrm{PH})$ was measured with millimeter ruler, LA was measured with leaf area meter LI 3100C (LI-COR Biosciences, Lincoln, United States of America), and SDM was determined as previously described.

Variables PH, LA and SDM of the forage and the weed were obtained through graphic analysis method applied to relative yield (Radosevich 1987), based on a replacement series. The data analysis model and its interpretation followed that described by Radosevich (1987).

Relative competition indices $(\mathrm{RC})$, relative grouping coefficient $(\mathrm{K})$ and competition coefficient $(\mathrm{C})$ were calculated based on $50 \%$ culture:competitor ratio. $\mathrm{RC}$ represents species $\mathrm{X}$ comparative growth in comparison to species $\mathrm{Y}$; $\mathrm{K}$ points out the relative dominance of a species over another; and C highlights the most competitive species (Cousens, 1991). The joint interpretation of these values (RC, $\mathrm{K}$ and $\mathrm{C}$ ) accurately indicates the competitiveness of the involved species. Accordingly, species $\mathrm{X}$ is more competitive than $\mathrm{T}$ when $\mathrm{RC}>1, \mathrm{~K}_{\mathrm{x}}>\mathrm{K}_{\mathrm{y}}$, and $\mathrm{C}>0$; on the other hand, species $\mathrm{Y}$ is more competitive than species $\mathrm{X}$ when $\mathrm{RC}<1, \mathrm{~K}_{\mathrm{x}}<\mathrm{K}_{\mathrm{y}}$, and $\mathrm{C}<0$ (Hoffman and Buhler, 2002). To be considered significant, at least two criteria must have significant differences (Bianchi et al. 2006). 
Differences in RY values recorded at ratios 25,50 and $75 \%$ plants in relation to RY values, in comparison to values recorded for hypothetic lines at the respective proportions, were calculated to statistically analyze relative yield (Bianchi et al. 2006). The $t$ test at $5 \%$ possibility level was used to test differences in the assessed indices in comparison to the hypothetical line (Roush et al. 1989; Hoffman and Buhler 2002) and to find statistical significance-at least two plant ratios had to present significant difference from each other (Bianchi et al. 2006).

The null hypothesis used to test RY and $\mathrm{C}$ differences were constituted based on the principle that if total relative yield (TRY) and $\mathrm{RC}$ were equal to zero $(\mathrm{H} 0=0)$, measured were equal to $1(\mathrm{H} 0=1)$, and, with respect to index $\mathrm{K}$, differences between $\mathrm{K}_{\mathrm{x}}$ and $\mathrm{K}_{\mathrm{y}}$ would be equal to zero: $\mathrm{H} 0=\left(\mathrm{K}_{\mathrm{x}}-\mathrm{K}_{\mathrm{y}}\right)=0$. Results recorded for morphological features $(\mathrm{PH}, \mathrm{LA}, \mathrm{SDM})$ of forage and weed (S. gallica) species were expressed in mean value per plant. Data normality was tested through ShapiroWilk test ( $\mathrm{p} \geq 0.05)$; therefore, data transformation was necessary. Next, variance analysis was carried out through $\mathrm{F}$ test $(\mathrm{p} \leq 0.05)$. In case of significant difference between treatments, their means were compared through Dunnett's test $(\mathrm{p} \leq 0.05)$ by taking into consideration monocultures as the untreated check in these comparisons.

\section{RESULTS AND DISCUSSION}

Relative yields were quite close to the hypothetical line plotted for plants cultivated (in separate) when white clover's $\mathrm{PH}$ was analyzed. However, forage presented significant differences at two plant proportions: 50:50 and 25:75 (forage:competitor). White clover hypothetical line was higher at the 50:50 ratio; this outcome points towards greater efficiency to capture resources available in the environment (Fig. 1).

White clover's PH was lower than the hypothetical line at the 25:75 proportion, in the first year (Fig. 1a). This outcome can highlight that bigger forage populations present higher performance than the expected. However, increase in the population of competitor plants at ratio $25: 75$ had effect on white clover due to competition, a fact that indicates that interspecific competition is higher than the effect of the intraspecific one-it is the most efficient competitor in the search for resources available in the environment. The RY of S. gallica presented concave line, but there was significant difference at ratio 25:75, when there was significant reduction in comparison to the hypothetical line representing the RY recorded for the competitor that was growing freely-without the presence of the sown culture.

In the second year, the graphic analysis applied to RY of white clover's PH plotted a concave line presenting significant deviation in comparison to the hypothetical line when the forage species was at the same ratio of the competitor (Fig. 1b). The RY of S. gallica, in its turn, presented different behavior depending on plant ratio; RY of the competitor was statistically higher than the hypothetical line at higher forage ratio. However, the RY of S. gallica was significantly lower than the hypothetical line at ratio 25:75 (forage:competitor) (Fig. 1b).

The behavior of white clover and S. gallica TRY and PH back in 2017 and 2018 was similar. There was trend of concave line formation, mainly at ratio 25:75 (forage:competitor), which means antagonism, i.e., there was growth loss in both species (Figs. 1a and 1b). This behavior points towards mutual loss between white clover and S. gallica when there was a large number of competitors at the assessed plant ratios, although there was statistical significance at only one plant ratio.

White clover and competitor responses recorded for LA can be seen in Figs. 1c and 1d. In 2017, forage's RY led to concave line, which has differed from the hypothetical line at two plant ratios, 50:50 and 25:75. This outcome highlights strong competition between species for resources in the environment. This same behavior was recorded for the RY of S. gallica, which once more showed that the competition took place due to the same resources. TRY differed at the 50:50 and 75:25 ratio; it recorded value less than the hypothetical line plotted for culture yield.

In the second year, RY results due to white clover LA were similar to that recorded in the previous year; it plotted a concave line, which was different from the hypothetical line at three tested plant ratios (Fig. 1d). This outcome highlights that the forage was strongly influenced by the presence of competitor S. gallica. On the other hand, RY recorded for the competitor resulted in convex line, different from values recorded in 2017, which is also different from the hypothetical line without competition at two plant ratios 50:50 and 25:75, which evidenced benefits to the competitor and that the weed was more efficient in capturing resources available in the environment. 
Plant height
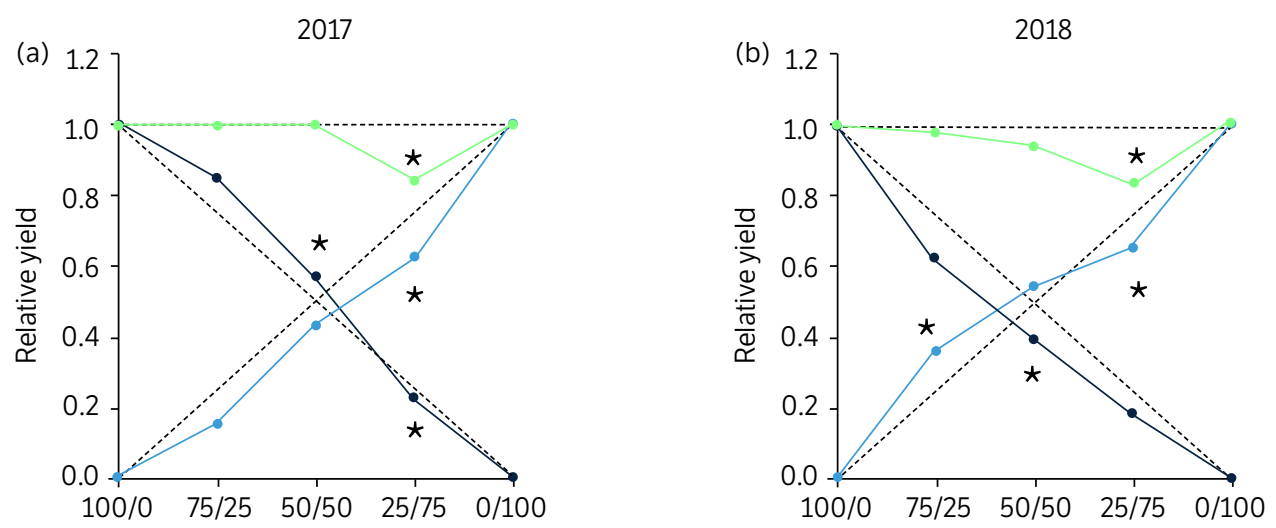

Leaf area
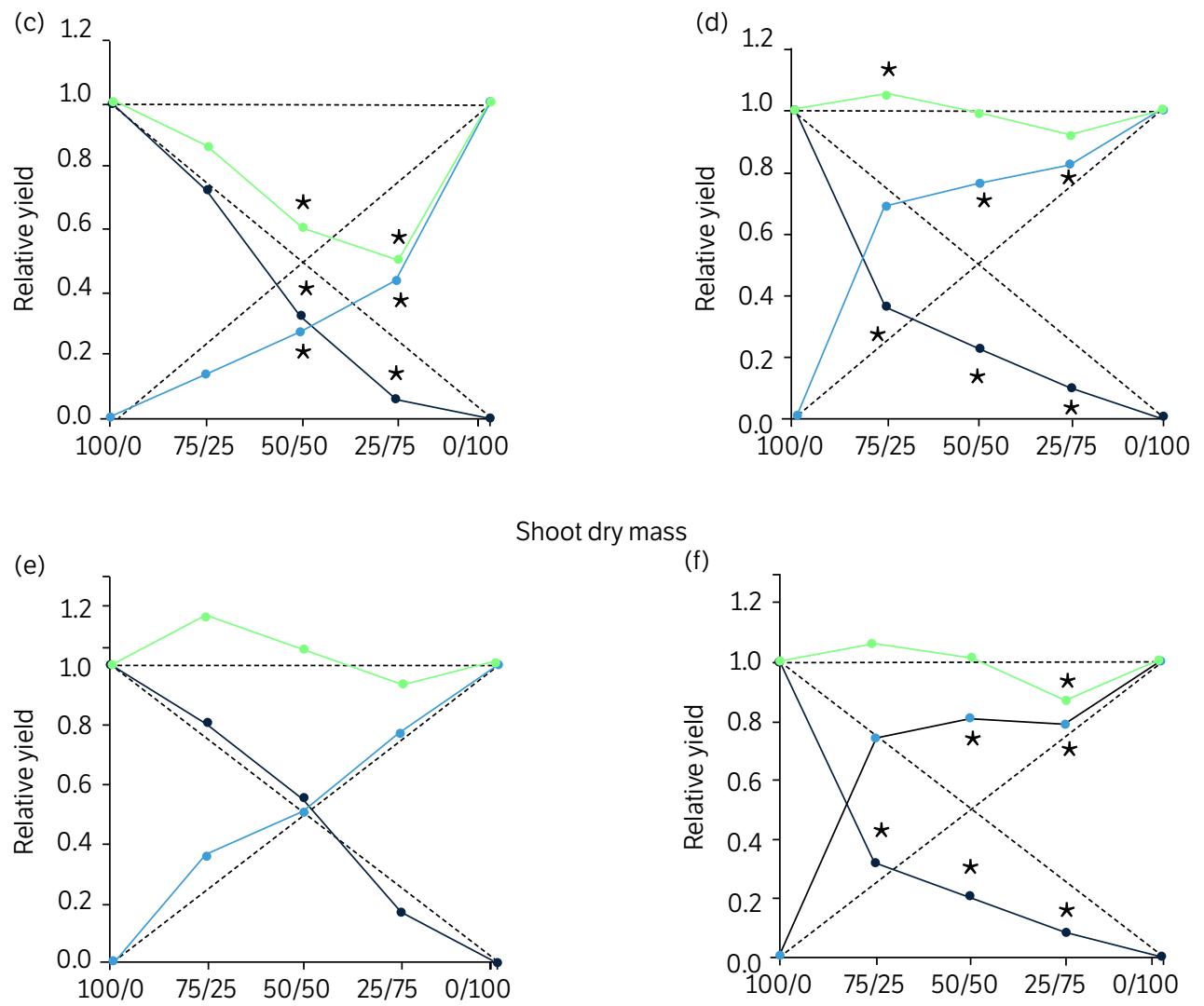

Shoot dry mass

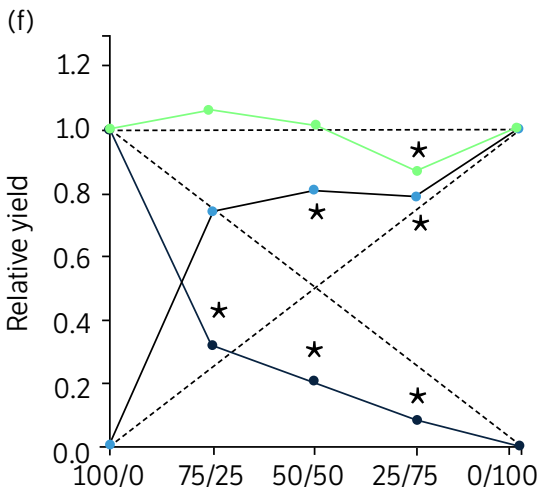

White clover / S. gallica ratio (\%)

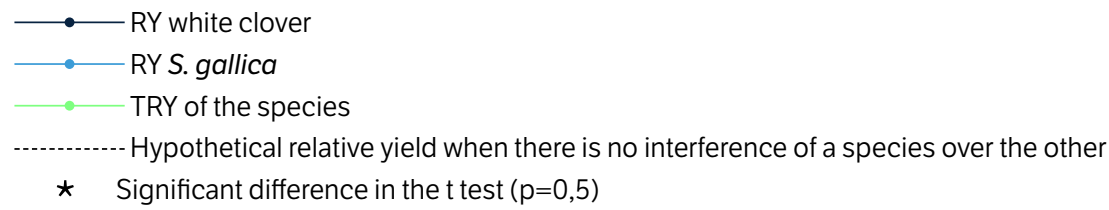

Figure 1. Relative yield (RY) and total relative yield (TRY) recorded for the ( $a$ and b) plant height, (c and d) leaf area and (e and f) shoot dry mass of white clover and Silene gallica (competitor). Faculdade de Agronomia Eliseu Maciel, Universidade Federal de Pelotas, Capão do Leão (RS), 2017 and 2018. 
In the second year, TRY was different from the hypothetical line in only one plant ratio; 75:25 (forager:competitor), which highlighted that white clover stands out at higher ratios (Fig. 1d). The behavior of the forage's RY explains the TRY's behavior, because white clover RY led to concave line and S. gallica's RY resulted in convex line. This process ended up compensating white clover's concave line, which could lead to TRY values much closer to the hypothetical line plotted for the cultures.

Variable SDM between white clover and S. gallica was used as an accurate and usual indicator of competition effects (Aschehoug et al., 2016). It was possible observing that there were no significant differences in species' behavior in the first year neither in RY nor in TRY (Figs. 1e and 1f), since the lines were quite close to the hypothetical lines plotted for species yield. As for the second year, behavior was different, white clover RY was influenced by the presence of the competitor, which resulted in concave line. This outcome statistically differed from the hypothetical line at all assessed plant ratios, which indicated that the competitor is less efficient than S. gallica.

The RY applied to the SDM of competitor S. gallica plotted convex line in the second year. This outcome was statistically different from the hypothetical line at two plant ratios, 50:50 and 25:75, which showed that increased weed population in the mixture made it more competitive than white clover, since it was more efficient in using resources available in the environment (Fig. 1f). Because two species have shown different RY behavior-white clover, concave line; and S. gallica, convex line-, the TRY of both species were quite close to the hypothetical line. They presented significant difference at ratio 25:75, which led to reduced expected yield. Based on SDM results, mainly in 2018, it was possible inferring that white clover has competition potential lower than that recorded for S. gallica.

The relative growth of variable PH (Table 1) in white clover and S. gallica in the first year showed that the forage species did not show significant difference in comparison to the untreated check, without the presence of the competitor. Back in the second year, white clover presented PH reduction at ratios 50:50 and 25:75 (forage:competitor), which has evidenced that, similar to the increase in the population of S. gallica plants, white clover plants have had negative response and presented reduced height.

Table 1. White clover response to the interference of competitor Silene gallica expressed in plant height (PH), leaf area (LA) and shoot dry mass (SDM) recorded in experiments conducted in replacement series. Faculdade de Agronomia Eliseu Maciel, Universidade Federal de Pelotas, Capão do Leão (RS), 2017 and 2018.

\begin{tabular}{|c|c|c|c|}
\hline \multirow{4}{*}{$\begin{array}{c}\text { Plant ratio } \\
\text { (forage:competitor) }\end{array}$} & \multicolumn{3}{|c|}{ Plant ratio (White clover:Silene gallica) } \\
\hline & $\mathrm{PH}(\mathrm{cm})$ & LA $\left(\mathrm{cm}^{2} \cdot\right.$ plant $\left.^{-1}\right)$ & SDM $\left(g \cdot\right.$ plant $\left.^{-1}\right)$ \\
\hline & \multicolumn{3}{|c|}{2017} \\
\hline & \multicolumn{3}{|c|}{ White clover } \\
\hline $100: 00(T)$ & 12.00 & 0.88 & 0.23 \\
\hline $75: 25$ & 13.56 & 0.85 & 0.25 \\
\hline $50: 50$ & 13.63 & $0.57^{\star}$ & 0.25 \\
\hline $25: 75$ & 10.69 & $0.21^{\star}$ & 0.15 \\
\hline \multirow[t]{2}{*}{ CV (\%) } & 15.85 & 51.87 & 35.13 \\
\hline & \multicolumn{3}{|c|}{ Silene gallica } \\
\hline $100: 00(T)$ & 16.19 & 1.08 & 0.38 \\
\hline $75: 25$ & 13.44 & $0.64^{*}$ & 0.39 \\
\hline $50: 50$ & 14.00 & $0.60^{*}$ & 0.38 \\
\hline $25: 75$ & $10.00^{*}$ & $0.60^{\star}$ & 0.55 \\
\hline \multirow[t]{3}{*}{ CV (\%) } & 21.89 & 43.13 & 35.13 \\
\hline & \multicolumn{3}{|c|}{2018} \\
\hline & \multicolumn{3}{|c|}{ White clover } \\
\hline $100: 00(T)$ & 17.27 & 67.34 & 0.62 \\
\hline $75: 25$ & 14.27 & $32.26^{\star}$ & $0.26^{\star}$ \\
\hline $50: 50$ & $13.68^{\star}$ & $30.31^{\star}$ & $0.26^{\star}$ \\
\hline $25: 75$ & $12.56^{\star}$ & $25.71^{*}$ & $0.21^{\star}$ \\
\hline \multirow[t]{2}{*}{ CV (\%) } & 17.98 & 52.55 & 57.99 \\
\hline & \multicolumn{3}{|c|}{ Silene gallica } \\
\hline $100: 00(T)$ & 20.34 & 73.38 & 0.77 \\
\hline $75: 25$ & 17.69 & 80.74 & 0.81 \\
\hline $50: 50$ & 21.99 & $112.06^{\star}$ & $1.25^{\star}$ \\
\hline $25: 75$ & $29.15^{\star}$ & $202.73^{\star}$ & $2.28^{\star}$ \\
\hline CV (\%) & 21.22 & 47.79 & 53.05 \\
\hline
\end{tabular}

${ }^{\star}$ Means are different from the untreated check $(T)$ in the Dunnett's test $(P \leq 0.05)$; CV: coefficient of variation. 
White clover presence made S. gallica's PH value decrease in 2017 at ratio 25:75, which means greater interspecific than intraspecific competition. However, in 2018, results were different from those recorded in the previous year, since S. gallica plants presented PH increase at ratio 25:75. This statistically differed from results recorded for the untreated check in the monocrop. Thus, intraspecific competition was higher than that recorded for the interspecific one, because smaller populations of S. gallica plants recorded higher height than the PH recorded for plants in the monocrop. Intraspecific competition in most studies appeared more important than the interspecific one and such finding allowed balance between plant populations (Adler et al. 2018).

Forage LA was influenced by the conditions in the two years of study, based on the analysis of interaction between white clover and S. gallica (Table 1), which presented significant reduction at ratios 50:50 and 25:75. This outcome indicated that white clover was more influenced by S. gallica plants, mainly when the ratio of these plants in the mixture was higher. In 2017, S. gallica showed the effects of interspecific competition in LA; however, in the second year, the weed seemed to benefit from the presence of forage even when the ratio was 25:75-LA was quite higher than the condition in monocrop.

With regards to SDM in the relationship between white clover and S. gallica in the first year, the influence of a species over the other was not significant (Table 1). However, in the second year, SDM yield recorded for white clover at three ratios in the mixture was significantly lower than that of the untreated check in the monocrop, which showed the effects of S. gallica.

Higher S. gallica competition potential was also confirmed by its SDM yield, which showed significant increase in comparison to the untreated check in the monocrop at ratios 50:50 and 25:75. This outcome evidenced that the weed was more competitive and that interspecific competition was more important in this case, differently from Adler et al. (2018), who showed intraspecific competition as the most important one in most studies.

$\mathrm{RC}, \mathrm{k}$ and $\mathrm{C}$ between forage and S. gallica plants were similar when their ratios were the same, as described in Table 2. The forage was considered more competitive than S. gallica when $\mathrm{CR}>1, \mathrm{Ka}>\mathrm{Kb}$ and $\mathrm{C}>0$ (Hoffman and Buhler, 2002). Significance, in at least two indices, was the criteria used to classify a species as more competitive than the other (Bianchi et al., 2006).

Table 2. Competition index between white clover and competitor Silene gallica, expressed in relative competition, relative grouping coefficients and competition recorded for plant structure variables (PH), leaf area (LA) and shoot dry mass (SDM) observed in experiments conducted in replacement series. Faculdade de Agronomia Eliseu Maciel, Universidade Federal de Pelotas, Capão do Leão (RS), 2017 and 2018.

\begin{tabular}{|c|c|c|c|c|}
\hline \multirow{2}{*}{ Variable } & Rc & Ка & $\mathbf{K b}$ & C \\
\hline & \multicolumn{4}{|c|}{ PH (2017) } \\
\hline \multirow[t]{2}{*}{ White clover: Silene gallica } & $1.34( \pm 0.15)^{\mathrm{ns}}$ & $1.32( \pm 0.10)^{\star}$ & $0.78( \pm 0.09)$ & $0.14( \pm 0.05)^{\star}$ \\
\hline & \multicolumn{4}{|c|}{ PH (2018) } \\
\hline \multirow[t]{2}{*}{ White clover: Silene gallica } & $1.12( \pm 0.16)^{\mathrm{ns}}$ & $1.32( \pm 0.33)^{\mathrm{ns}}$ & $1.09( \pm 0.24)$ & $0.04( \pm 0.08)^{\star}$ \\
\hline & \multicolumn{4}{|c|}{ LA (2017) } \\
\hline \multirow[t]{2}{*}{ White clover: Silene gallica } & $1.24( \pm 0.22)^{\mathrm{ns}}$ & $0.49( \pm 0.05)^{\mathrm{ns}}$ & $0.39( \pm 0.05)$ & $0.05( \pm 0.05)^{\star}$ \\
\hline & \multicolumn{4}{|c|}{ LA (2018) } \\
\hline \multirow[t]{2}{*}{ White clover: Silene gallica } & $0.30( \pm 0.06)^{\star}$ & $0.31( \pm 0.09)^{\star}$ & $3.73( \pm 1.03)$ & $-0.54( \pm 0.06)^{\star}$ \\
\hline & \multicolumn{4}{|c|}{ SDM (2017) } \\
\hline \multirow[t]{2}{*}{ White clover: Silene gallica } & $1.12( \pm 0.16)^{\mathrm{ns}}$ & $1.32( \pm 0.33)^{\mathrm{ns}}$ & $1.09( \pm 0.24)$ & $0.04( \pm 0.08)^{\star}$ \\
\hline & \multicolumn{4}{|c|}{ SDM (2018) } \\
\hline White clover: Silene gallica & $0.26( \pm 0.06)^{\star}$ & $0.28( \pm 0.09)^{\star}$ & $6.66( \pm 2.28)$ & $-0.60( \pm 0.09)^{\star}$ \\
\hline
\end{tabular}

With respect to white clover growth along with S. gallica in the first year, based on $\mathrm{PH}$, the forage showed its superiority in the presence of the competitor based on the relative grouping confidence and on $\mathrm{C}$ index. However, the forage ended up losing competition with S. gallica in the second year, based on LA and SDM. The three LA indices presented statistical significance, but white clover relative competition $<1$, along with $\mathrm{Ka}<\mathrm{Kb}$ and with competition coefficient $(\mathrm{C}<0)$, indicated that $S$. gallica is more competitive than white clover.

Plant height is an important feature for species growth and development, and space occupation in the environment, since it is closely related to plants' efficiency to light capture (Aslani and Saeedipour 2015), but competition between plants 
can change this feature. Forages showed that the presence of a competitor caused low $\mathrm{PH}$ reduction in comparison to the expectation when these plants were cultivated in separate, although white clover was the species presenting weaker habit in comparison to the weed. However, such reduction can affect plants' ability to capture light, since it is closely related to competitiveness (Den Hollander et al. 2007; Kruidhof et al. 2008).

Competitors' increased PH and LA could reduce individual liquid carbon accumulation in plants, but it would allow these plants to stand out in comparison to forages (Aschehoug et al. 2016). Greater investment in branches and leaves, along with lower carbon accumulation-which is boosted by the need of anticipating light capture in relation their neighbors-, can reduce the competitive ability of these plants (Aschehoug et al. 2016).

Changes in forages' leaf area were observed in cases in which S. gallica had negative effect on this variable, in the two assessed years, in white clover; it indicates that this variable was strongly affected by competition. Similar results were observed in the competition among sorghum with Urochloa plantaginea and sorghum with Euphorbia heterophylla, when weeds led to significant reduction in sorghum's LA (Galon et al. 2018).

Overall, competition had little influence on variable SDM, only the white clover culture recorded significant reduction in comparison to the forage monocrop in 2018. White clover reduction was recorded in the first year, and it showed similar competition potential between species. But the variation recorded for white clover in the second year showed that the culture was affected by the competitor. This outcome makes it clear that white clover is less competitive than S. gallica, because SDM yield reduction is often observed in less competitive plants (Aminpanah and Javadi 2011; Rezaeieh et al. 2015).

Higher competition potential of weeds over the forages was also observed in the study between forage species: ryegrass and fescue (Festuca arundinacea Schreb), which presented lower competition potential than that of five weed species: Solidago altissima L., S. canadensis L., S. gigantea Aiton, S. virgaurea L. and Euthamia graminifolia (L.) Nutt., mainly when it comes to biomass production (Szymura et al. 2018).

Every time a weed species causes SDM yield reduction in the crop, one says that the weed is more competitive than the crop; therefore, it is recommended to manage the weeds, even when the population is small, in order to avoid losses due to competition (Forte et al. 2017). Forages belonging to family Fabaceae, such as white clover, are featured by their phenotypic plasticity (Fazlioğlu et al. 2018); they can present behavioral differences between growth seasons, and it results in different forage yields (Tracy et al. 2016; Chapman et al. 2017). Differences in the maximal, minimal, and mid temperatures, between 2017 and 2018, may have caused differences in the behavior of forages.

The maximal temperatures in the 2018 experiment were higher than the maximal temperatures recorded in 2017; minimal temperatures in 2018 were lower than the minimal temperatures in 2017, what indicated wider thermal amplitude in 2018. Temperatures in 2017 were lower than in 2018, on average.

Competitiveness relationship between plants can also change from one year to another-there was variation in the individual behaviors of the species in question (Ergon et al. 2016). This differentiated plasticity and behavior due to cultivation conditions may have led to the results recorded in the current study-it is impossible clearly assessing similar behavior in the two assessed years. The behavior recorded in second year was the same of the first one. Biomass yield of fescue and Lolium perenne L. has reduced approximately 70 and $50 \%$, respectively, from one year to the other; white clover and red clover biomass yield reduced by 30 and 20\%, respectively, in different assessment years (Ergon et al. 2016).

The greatest competition potential of any plant is related to its ability to capture light in anticipation to its competitors (Kruidhof et al. 2008). Therefore, no matter the species that gets to establish itself in anticipation, be it white clover or S. gallica, it will have advantage in niche occupation (Schuster et al. 2013).

Fast establishment, greater and faster soil coverage increase crop competition potential when it is grown with the weed (Kruidhof et al. 2008). Forages such as white clover stand out in temperate climate zones, but they are in disadvantage in relation to competitors, since they present slow establishment (Barcellos et al. 2008; Lustosa et al. 2011). Thus, all the advantage possible must be given to forages at their sowing. It is important knowing the effect of competition with the weed and establishing integrated control strategies, such as areas lacking weeds with tolerated harming seeds (preventive management) in forage seed production fields. It is so due to lack of chemical control options resulting from the selective registration of herbicides in Brazil, for example, the adoption of sowing within the recommended times at appropriate densities, in order to give advantages to the forage. 


\section{CONCLUSION}

There is phenotypic plasticity in forages from temperate climate zones such as white clover, which evidences that competition relationships with S. gallica change due to the proportion of plants composing the association. The species presenting similar competition ability, but the weed tended to be more skilled to it than white clover.

\section{AUTHORS' CONTRIBUTION}

Conceptualization: Rockenbach, D. and Lamego, F.; Methodology: Rockenbach, D., Bastiani, M. O., Caratti, F. C., Agostinetto, D. and Lamego, F.; Investigation: Rockenbach, D and Balbinot, A.; Writing - Original Draft: Rockenbach, D. and Lamego, F.; Writing - Review and Editing: Bastiani, M. O., Agostinetto, D., Caratti, F.C., Balbinot, A. and Lamego, F.; Funding Acquisition: Lamego, F.; Resources: Lamego, F.; Supervision: Lamego, F. and Agostinetto, D.

\section{DATA AVAILABILITY STATEMENT}

Data will be available upon request.

\section{FUNDING}

Coordenação de Aperfeiçoamento de Pessoal de Nível Superior

[http://doi.org/10.13039/501100002322]

Empresa Brasileira de Pesquisa Agropecuária (Embrapa)

[http://doi.org/10.13039/501100003046]

Project number 22.14.03.013.00.00.

Conselho Nacional de Desenvolvimento Científico e Tecnológico

[http://dx.doi.org/10.13039/501100003593]

Grant No: 305816/2016-0

\section{ACKNOWLEDGMENTS}

The authors are thankful to UFPel for financial support to experiments conduction.

\section{REFERENCES}

Adler, P. B., Smull, D., Beard, K. H., Choi, R. T., Furniss, T., Kulmatiski, A., Meiners, J. M., Tredennick, A. T. and Veblen, K. E. (2018). Competition and coexistence in plant communities: intraspecific competition is stronger than interspecific competition. Ecology Letters, 21(9), 1319-1329. https://doi.org/10.1111/ele.13098

Aminpanah, H. and Javadi, M. (2011). Competitive ability of two rice cultivars (Oryza sativa L.) with barnyardgrass (Echinochloa crusgalli (L.) P. Beauv.) in a replacement series study. Advances in Environmental Biology, 5(9), 2669-2675. 
Aschehoug, E. T., Brooker, R., Atwater, D. Z., Maron, J. L. and Callaway, R. M. (2016). The mechanisms and consequences of interspecific competition among plants. Annual Review of Ecology and Systematics, 47, 263-281. https://doi.org/10.1146/annurev-ecolsys-121415-032123

Aslani, S. and Saeedipour, S. (2015). Competitive interaction of canola (Brassica napus) against wild mustard (Sinapis arvensis) using replacement series method. Walia Journal, 31(S2), 111-116.

Barcellos, A. O., Ramos, A. K. B., Vilela. L. and Martha Junior, G. B. (2008). Sustentabilidade da produção animal baseada em pastagens consorciadas e no emprego de leguminosas exclusivas, na forma de banco de proteína, nos trópicos brasileiros. Revista Brasileira de Zootecnia, 37, 51-67. http://dx.doi.org/10.1590/S1516-35982008001300008

Bianchi, M. A., Fleck, N. G. and Lamego, F. P. (2006). Proporção entre plantas de soja e plantas competidoras e as relações de interferência mútua. Ciência Rural, 36(5), 1380-1387. http://dx.doi.org/10.1590/S0103-84782006000500006

Brasil. Ministério da Agricultura, Pecuária e Abastecimento. (2013). Instrução Normativa MAPA 46/2013. Dispõe sobre a relação de espécies de sementes nocivas toleradas e proibidas na produção, na comercialização e no transporte de sementes nacionais e importadas de grandes culturas, forrageiras, olerícolas, flores, ornamentais. Brasilia: Ministério da Agricultura, Pecuária e Abastecimento .

Chapman, D. F., Lee, J. M., Rossi, L., Edwards, G. R., Pinxterhuis, J. B. and Minnee, E. M. K. (2017). White clover: the forgotten component of high-producing pastures? Animal Production Science, 57(7), 1269-1276. https://doi.org/10.1071/AN16453

Cousens, R. (1991). Aspects of the design and interpretation of competition (interference) experiments. Weed Technology, 5(3), 664673. https://doi.org/10.1017/S0890037X00027524

Den Hollander, N. G., Bastiaans, L. and Kropff, M. J. (2007). Clover as a cover crop for weed suppression in an intercropping design I. Characteristics of several clover species. European Journal of Agronomy, 26(2), 92-103. https://doi.org/10.1016/j.eja.2006.08.011

Ergon, Å., Kirwan, L., Bleken, M. A., Skjelvåg, A. O., Collins, R. P. and Rognli, O. A. (2016). Species interactions in a grassland mixture under low nitrogen fertilization and two cutting frequencies: 1 . dry-matter yield and dynamics of species composition. Grass and Forage Science, 71(4), 667-682. https://doi.org/10.1111/gfs.12250

Fazlioğlu, F., Wan, J. S. H. and Bonser, S. P. (2018). Phenotypic plasticity and specialization along an altitudinal gradient in Trifolium repens. Turkish Journal of Botany, 42(4), 440-447. https://doi.org/10.3906/bot-1711-21

Forte, C. T., Basso, F. J. M., Galon, L., Agazzi, L. R., Nonemacher, F. and Concenço, G. (2017). Habilidade competitiva de cultivares de soja transgênica convivendo com plantas daninhas. Revista Brasileira de Ciências Agrarias, 12(2), 185-193. https://doi.org/10.5039/ agraria.v12i2a5444

Galon, L., Santin, C. O., Andres, A., Basso, F. J. M., Nonemacher, F., Agazzi, L. R., Silva, A. F., Holz C. M. and Fernandes, F. F. (2018). Competitive interaction between sweet sorghum with weeds. Planta Daninha, 36, 1-13. http://dx.doi.org/10.1590/s0100-83582018360100053

Hoffman, M. L. and Buhler, D. D. (2002). Utilizing Sorghum as a functional model of crop-weed competition. II. Effects of manipulating emergence time or rate. Weed Science, 50(4), 466-472. https://doi.org/10.1614/0043-1745(2002)050[0473:USAAFM]2.0.CO;2

Kruidhof, H. M., Bastiaans, L. and Kropff, M. J. (2008). Ecological weed management by cover cropping: effects on weed growth in autumn and weed establishment in spring. Weed Research, 48(6), 492-502. https://doi.org/10.1111/j.1365-3180.2008.00665.x

Lustosa, S. B. C., Machado, D., Baldissera, T. C., Moraes, A. and Sandini, I. (2011). Experiências de integração lavoura-pecuária na região central do Paraná. Synergismus Scyentifica, 6(2), 1-5.

Radosevich, S. R. (1987). Methods to study interactions among crops and weeds. Weed Technology, 1(3), 190-198. https://doi.org/10.1017/ S0890037X00029523

Radosevich, S. R., Holt, J. and Ghersa, C. (2007). Ecology of weeds and invasive plants: relationship to agriculture and natural resource management. 3. ed. New Jersey: Wiley-Interscience. 
Rezaeieh, A. D., Aminpanah, H. and Sadeghi, S. M. (2015). Competition between rice (Oryza sativa L.) and (barnyardgrass (Echinochloa crus-galli (L.) P. Beauv.) as affected by methanol foliar application. Anais da Academia Brasileira de Ciências, 87(2), 879-890. http:// dx.doi.org/10.1590/0001-3765201520140413

Rizzardi, M. A., Fleck, N. G., Vidal, R. A., Merotto Jr., A. J. and Agostinetto, D. (2001). Competição por recursos do solo entre ervas daninhas e culturas. Ciência Rural, 31(4), 707-714. http://dx.doi.org/10.1590/S0103-84782001000400026

Roush, M. L., Radosevich, S. R., Wagner, R. G., Maxwell, B. D. and Petersen, T. D. (1989). A comparison of methods for measuring effects of density and proportion in plant competition experiments. Weed Science, 37(2), 268-275. https://doi.org/10.1017/S0043174500071897

Schuster, M. Z., Szymczak, L. S., Lustosa, S. B. C., Pelissari, A., Moraes, A. and Francisco, R. (2013). Interferência de plantas daninhas no estabelecimento do trevo branco como cultura forrageira. Ciência Rural, 43(12), 2148-2153. http://dx.doi.org/10.1590/ S0103-84782013001200005

Szymura, M., Szymura, T. H., Wolski, K. and Świerszcz, S. (2018). Can native grass species outcompete invasive goldenrods? Results of a replacement series experiment. Weed Research, 58(4), 304-317. https://doi.org/10.1111/wre.12306

Tracy, B. F., Albrecht, K., Flores, J. P., Hall, M., Islam A., Jones G., Lamp W., MacAdam J. W., Skinner, H., Teutsch, C. (2016). Evaluating grass-legume forage mixtures across different environments. Crops \& Soils Magazine, 56(4), 2026-2034. https://doi.org/10.2135/ cropsci2015.09.0553 